\title{
Bemerkungen zu dem hebräischen Texte Jesus Sirachs und seiner neuesten Übersetzung.
}

Von Professor J. C. Matthes in Hilversum.

In der neulich herausgegebenen ersten niederländischen Übersetzung des hebräischen J. S. - MATThes en Dyserinck, De Spreuken van Jezus Sirach uit het Hebreeuwsch vertaald, 's-Gravenhage Martinus Nijhoff, I908 - fehlten Raum und Gelegenheit für einen kritischen Kommentar. Das Buch sollte bloß die Übersetzung selbst ohne Bemerkungen geben. Die Redaktion der ZAW ist jedoch so freundlich, mir einige Seiten ihrer Zeitschrift zur Verfügung $z u$ stellen, damit dasjenige, das im Buche nicht geschehen konnte, hier nachgeholt würde. Fur diese Bemerkungen übernehme ich allein die Verantwortlichkeit; Herr Dr. DYSERINCK hat sich daran nicht beteiligt.

Wie Jedermann weiß, haben schon Viele sich mit dem hebraischen Sirachtexte beschäftigt, u. a. Schechter, LEvy, Strack, Peters, RySSEL und SMEND. Die Arbeit des letztgenannten ist glanzend. Er hat m. E. auf diesem Gebiete das Beste und Vollständigste geliefert, das bis heute $z u$ erreichen war. Darum ist auch in der neuen holländischen Übersetzung besondere Rücksicht auf SMENDs Kommentar und seine Lesarten genommen.

Doch wird hier nicht über alle von SMEND vorgetragenen Textänderungen gehandelt. Wo die holländischen Übersetzer SMEND beistimmten, brauchte ich seiner Auseinandersetzung kaum ein Wort zuzufügen und noch weniger sie zu erwähnen. Denn das von ihm geschriebene hier zu wiederholen, hätte natürlich keinen $Z$ weck. Bloß da, wo die holländischen Übersetzer meinten, SMENDs Lesarten oder auch seine Texterklärungen verwerfen $z u$ müssen, wird von den Abweichungen in den nächstfolgenden Seiten Rechenschaft gegeben. SMENDs Name ist dabei abgekürzt zu SM; weiter ist $\mathrm{P}=$ PETERS $_{\bullet}$, $\mathrm{R}=$ RySSEL (Ed.

I Peters hat zwei Bücher über Sirach herausgegeben: einen Kommentar deutsch; nnd den hebräischen Text mit lateinischer Übersetzung. Ich unterscheide sie, wo nötig, als $\mathbf{P r}$ und $\mathbf{P}^{2}$.

Zeitschrift f. d. alttest. Wiss. Jahrg. 29. 3909. 
KAUTZSCHI), und MD - die neue holländische Úbersetzung von Matrhes und Dyserinck. Diese UUbersetzung wird hier jedoch nicht nach dem holländischen Wortlaute zitiert, sondern, damit sie allgemein verständlich sei, in deutscher Ubersetzung des holländischen Textes. $\mathrm{H}$ ist $=$ Hebr. Text; Gr $=\mathrm{LXX}$; Syr $=$ Peschitto.

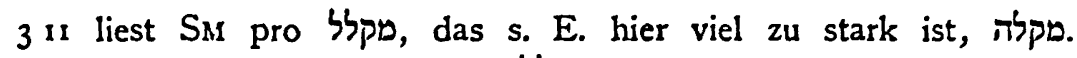
Doch auch Ex 2I 17 wird der מקלל אמו מקל Frevler genannt, der den Tod verdient. Die Notwendigkeit der Änderung läbt sich also nicht einsehen. Der alttestamentliche Sprachgebrauch ist von Sirach befolgt.

3 12a SM: "mein Sohn, nimm dich des Alters deines Vaters an". MD: "mein Sohn, beharre in der Verehrung deines Vaters". Ebenso P: „fili mi, persevera in honore patris“. $H$ hat: התחוק בכבד אביך, was einen guten Sinn gibt und ohne Grund von $S_{M}$ geändert wird in החזיק בשיבת אביך. Dies bedeutet auch nicht das, was SM übersetzt, sondern eher: „halte das Alter deines Vaters fest", was keinen Sinn gibt.

$320^{\circ}$ SM: „Denn groß ist die Macht des Herrn“, MD: „Denn groß

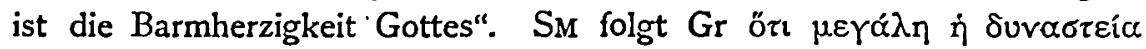

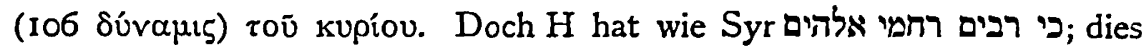
ist ursprünglich. Weil Gott barmherzig ist, findet der Demütige Barmherzigkeit bei ihm. Mit der Große Gottes hat das nichts zu tun.

4 Ia $^{\mathrm{a}}$ SM: „Mein Sohn, entziehe dem Armen nicht den Unterhalt"; MD: „mein Sohn, sieh nicht geringschätzig auf das Leben des Armen

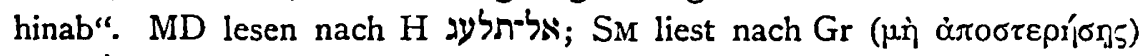
אל תגרע. Da aber dem Armen der Unterhalt fehilt, kann er dessen auch nicht beraubt werden; deshalb hat $\mathrm{H}$ den guten Text, den MD ubersetzen.

- 4 26b SM: „Schäme dich nicht, deine Sünden zu bekennen“; MD: „Schäme dich nicht, dich von Sünde zu bekehren“, vgl. P: „Ne confundaris reverti a peccato" nach H אל תבוש לשוב מעון. Vom Sündenbekenntnis redet der Text nicht.

6 I $\mathrm{b}$ SM: „(mancher Freund) spielt den Hêrrn gegenuber deinen Sklaven"; MD: ,und in deinem Mißgeschick entflieht er (der Freund) dir", nach H וברעתך "תנזה ממך. Ebenso P: ,et in calamitate tua fu-

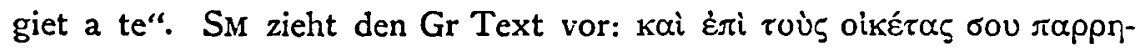

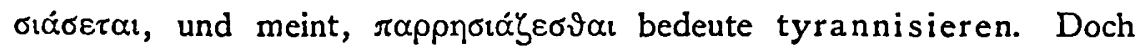
.Hes $163_{30}$, wo THEODOTION dieses tyrännisieren so ausgedrückt

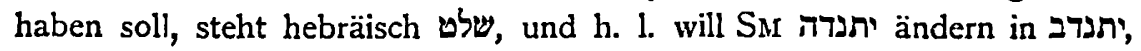
indem er für ובעבדך (H) liest, deine Dienerschaft. Doch 
woraus geht hervor, daß התנדב tyrannisieren bedeutet; es ist vielmehr freiwillig geben oder sich freiwillig beweisen, I Chr 295 f., Neh I 2 , Tg Ps I IO 3. 'Die Textänderung SM's empfiehlt sich also keineswegs. Wenn er weiter behauptet, dab der Gegensatz zu 6 I ${ }^{a}$ nicht 6 I ${ }^{b}$, sondern erst $61_{12}$ folgen kann, ubersieht er die Analogie v. 8 und 10, wo die b's auch Gegensätze zu den a's bilden.

6 r6a SM: „Ein treuer Freund ist ein Lebenszauber"; MD: „Ein treuer Freund ist ein Lebensbeutel" nach dem Text $\mathrm{H}$, der mit Rücksicht auf I Sam 2529 richtig sein kann. „Unklar" (SM) ist der Ausdruck wohl; aber

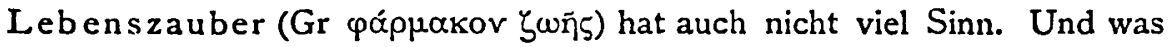
hat dann in $\mathrm{H}$ gestanden? - Vielleicht ist צור צurrumpiert und hat Sirach sagen wollen, der wahre Freund sei ein Felsen, worauf man bauen kann. Ich halte dies fur das Wahrscheinlichste.

$629^{\mathrm{a}}$ SM: „Und es wird ihre (der Weisheit) Fessel dir zu einem herrlichen Standort"; MD. :,und ihr Netz wird eine starke Burg“, d. h. „eine Abwehr aller feindlichen Gewalt sein“. SM: (Fessel) folgt Gr

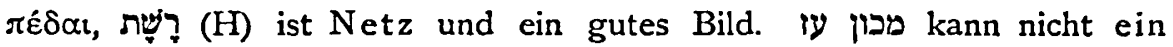
herrlicher Standort sein, da 1 Feste, Festigkeit, Stärke bedeutet; Herrlichkeit ist תרุณฺุ vgl. Ps 966 . Beide Bilder, Netz und starke Feste, drücken den Begriff der.Abwehr und des Schutzes aus.

$73 \mathrm{I}^{\mathrm{b}}$ 政 ist ihr Teil, der Teil Gottes und des Priesters $73^{\mathrm{a}}$;

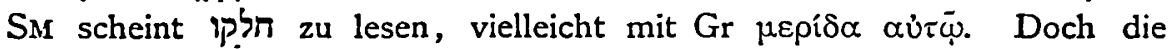
Änderung ist unrichtig; darum MD ,gib (ihnen) ihren Teil“.

84 ist לנדיבים, wie SM bemerkt, verderbt. Gr זpóyovor will vieileicht den Begriff Edle ausdrücken; aber dieser Begriff palit hier nicht: "Gehe nicht mit dem Toren um, damit er nicht die Edlen verachte" dies kann Sirach nicht haben sagen wollen. Darum lesen MD נכתים, und übersetzen: ,;Gehe nicht mit dem Toren um, damit er redliche Worte (die du ihm sagst) nicht verachte". תרניל, entweder Pi'el oder Hif'il, ist bei $\mathrm{Gr}$ жро́лац६, nach SM scherze, aber diese Bedeutung läbt sich nicht nachweisen.

$98^{\circ}$ SM: „Durch Betrachtung einer Frau sind viele umgekommen"; MD: „Durch die Schönheit einer Frau sind viele umgekommen“. H: בעד מעד אשה השחתו רבים , bei P: Propter mulierem multi perierunt. Doch ist in der Bedeutung aus Ursache von nicht belegt". - Der Talmud

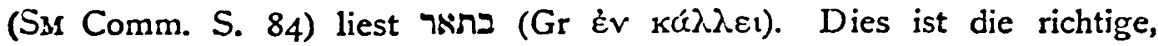
ursprüngliche Lesart. Warum $\mathrm{S}_{\mathrm{M}}$, der sie im Kommentare anerkennt, in der Übersetzung sie mit durch Betrachtung ersetzt, ist nicht deutlich.

9 1 ${ }^{d}$ SM: „wenn er alt ist, dann magst du ihn (den Wein) trinken". 
H: וישן אחר תשתינו. MD darum: dann magst du ihn spater trinken. SM streicht אח, doch so wird der Stichos zu kurz.

9 17 SM: "Von handfertigen Meistern wird bewaltigt das Kunstwerk". MD: "Von handfertigen Meistern wird das Kunstwerk gemacht." $\mathrm{H}$ "חש

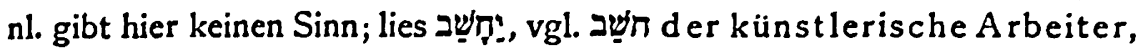

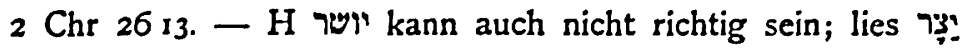

$917^{\mathrm{b}} \mathrm{SM}$ : „und Herrscher uber sein Volk ist der redefertige Weise“, MD: „und Herrscher über sein Volk ist der Weise". Doch richtig hat SM (vgl. 5 13), das in H zu $1918^{a}$ gehört, mit $1917^{b}$ verbunden. חכם ביטה $191^{17^{a \beta}}$ ist der Weise in Worten, im Gegensatz zu den Weisen in Handarbeit $1917^{a a}$.

אשר בתייו יורם גויו 10 איפ, MD: „er dessen Leib bei seinem Leben voll Würmer ist". Falsch SM: „er dessen Eingeweide bei seinem Leben verfaulen". Falsch auch P: "quoniam in vita eius proiicit ea corpus eius". יורם kommt nicht von רמה werfen, sondern ist Hof'al von רמם, wie Ex r6 20: „da wurde es voll Würmer".

I0 10 SM: Der Ansturm der Krankheit spottet des Arztes". In seinem Wörterverzeichnis S. 80 ubersetzt er 哝 mit: schneller Lauf.

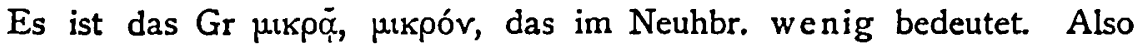
ist der Sinn des Verses: „in kurzem (= bald) spottet die Krankheit des Arztes", nicht umgekehrt: „der Arzt spottet der Krankheit" (WELLH.).

IO 17 MD folgen $H$, der zweimal טמרץ hat, und übersetzen: ,Er hat sie weggerissen aus der Erde und ihr Gedächtnis vertilgt von der Erde“"

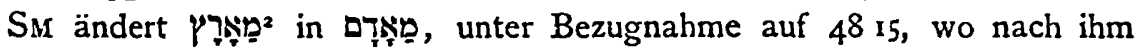
das doppelte ארץ auch falsch ist. Da jedoch sowohl $\mathrm{Gr}$ als $\mathrm{H}$ es dort liest, ist es gewi@ an beiden Stellen ursprünglich und richtig.

I 6b DM: „Hochgeehrte wurden in des Feindes Macht gegeben“, $\mathrm{H}$ נתנו- ביד Denne nachfolgenden Genitiv hat diese Bedeutung, vgl. 2 Chr 25 20, wo also der Vorschlag OoRTs (Em. p. 28), pro ביד

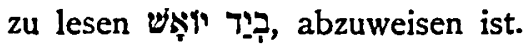

I $9^{a}$ SM: „Wo du machtlos bist, ereifere dich nicht, d. h. gerate nicht in Zorn". MD: „wo keine Kränkung ist, ereifere dich nicht". Ohne Zweifel ist $\mathrm{H}$ תאת, wie auch $\mathrm{S}_{M}$ annimmt, Schreibfehler für

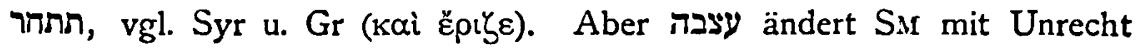

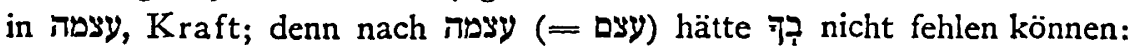

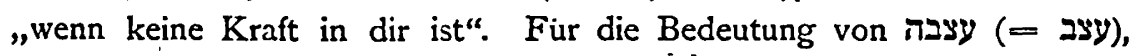
- Kränkung, vgl. Prv I 5 I.

II $23^{\text {a }}$ SM: "Sage nicht: wozu tat ich mein Werk?"، MD: „Sage nicht: wozu tat ich sein (Gottes) Gefallen?" d. h. Gottes Willen. H 
hat $3 D \pi$ mit einem letzten unlesbaren Buchstaben. SM suppliert, wie $P$, ein "und übersetzt dann ח ח mein Werk, $P$ beneplacitum meum. Das letzte aber gibt hier keinen Sinn, und Werk kann nicht bedeuten. Darum ist es besser ein waw zu supplieren und חצמ zu lesen.

I I $3^{\text {b }} \mathrm{MD}$ : „und deinen Tugenden hängt er Frevel an“; fast wie SM, nur daß dieser במחמרך mit Sing. übersetzt: ,und deiner herrlichsten Tugend hängt Ruchlosigkeit an." Doch er schreibt selbst במחמדיך, vgl. auch RYSSEL: „den trefflichsten Dingen“. Falsch P: „,et in electis tuis facit coniurationem". Bei Sirach hat p die Bedeutung freveln, vgl. 78.

13 Ib SM: ,wer mit dem Übermütigen umgeht, über den kommt dessen Handlungsweise“; MD: „Wer mit dem Spotter umgeht, lernt dessen Weg". 'ל ist nicht = úreńpavos (Gr), sondern bedeutet den frivolen Verächter der Religion und der Sittlichkeit. - $\mathrm{H}$ hat weiter

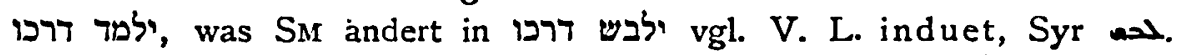
$R$ verteidigt den Ausdruck mit dem syrischen לבישות בדמותא, ubersieht aber daß die Praep. \. h. 1 fehlt. Jedermann wird jedoch einsehen, daß : ,,uber den kommt dessen Handlungsweise" keinen Sinn gibt. Im Kommentar hat $S_{M}$ : „ihn wird der Weg des Übermütigen bedecken“, was auch keinen richtigen Sinn gibt. Also ist die Textanderung SM's nicht gerechtfertigt, dagegen ist die LA H's vorzüglich.

13 22b, SM $1323^{\text {b: }}$ "seine Worte erheben sie bis an die Wolken"; MD: „sie erheben seine Einsicht bis an die Wolken“, weil שכלו nur das bedeuten kann.

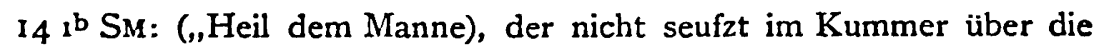
Sünde“, MD: („H. d. M.), über den nicht trauert sein trübes Herz". Von der Sünde steht nichts im Text, der in H lautet ולא אבה עליו דון לבו אבה ist, wie SM' bemerkt, Schreibfehler für אנה, vgl. Jes 316; 198

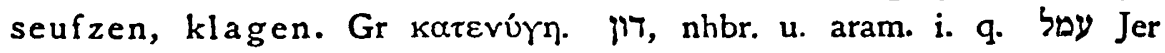
201838 10 517 PS 3111 , von 'T, או

I4 $6^{\text {b }}$ SM: „Die Strafe seiner Schlechtigkeit kommt von ihm selbst". MD: „Die Strafe seiner Schlechtigkeit ist bei ihm selbst“, $R$ erklarend:

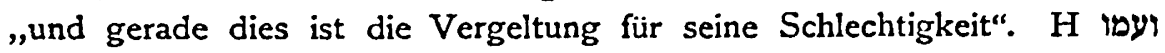
תשלומת רעתו

I4 $9^{2}$ MD: „Fur das Auge des Verarmten ist sein Besitz zu klein"; SM: „Für das Auge des Habgierigen ist sein Besitz zu klein". Der Gedanke Sirachs ist, dab der Verarmte, wenn er seinen jetzigen Zustand mit dem früheren, wohlhabenden vergleicht, seinen Besitz viel zu klein findet. H hat בעין כושל מעם הוא תלקו Nun gibt SM zu, dab כושל im 
nhbr. arm, verarmt bedeutet, doch nichtsdestoweniger hält er das

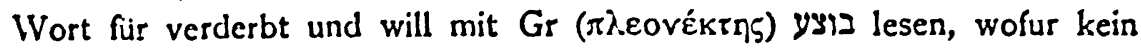
Grund vorliegt, weil $\mathrm{H}$ einen guten Sinn gibt.

$152^{b}$ כעשת נעורים ein junges Weib". Eigentlich bedeutet der hebräische Ausdruck: „das IVeib der Jugend d. h. des Mannes", vgl. Mal 225. Doch ein Weib der Jugend ist in der Übersetzung schwer verstandlich.

I5 $15^{\mathrm{a}}$ haben MD wie SM: „Wenn es dir beliebt, hältst du das Gebot"; doch v. 15b lautet bei SM: "und Treue ist es, das ihm Wohlgefällige zu tun"; bei MD: „es ist aber klug, das ihm Wohlgefällige zu tun". Auch P hat ,et intelligentia est facere voluntatem eius"; dagegen $R$ (mit ganz falscher Auffassung): ,und Treue uben kannst du, wenn es dir gefällt". Es handelt sich besonders darum, ob mit $\mathrm{H}$

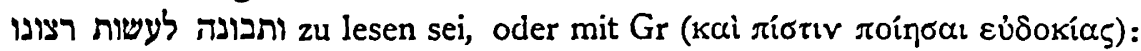
ואטמנה לעשות רצונו ל Zweifelsohne ist die LA von $\mathrm{H}$ richtig; sie will sagen, obgleich es dem Menschen frei steht, die göttlichen Gebote zu halten, oder nicht zu halten, ist es klug, Gottes Willen zu tun. Gr gibt keinen guten Sinn, vgl. HERKENNE, De veteris Latinae Ecclesiastici Capitibus I-XLIII, p. 148. Mit Unrecht hat also $\mathrm{SM}_{\mathrm{M}}$ die LA von $\mathrm{Gr}$ der viel besseren von $H$ vorgezogen.

I6 16 (SM u. P 16 18) hat SM vier Zeilen, wahrend MD drei Zeilen ubersetzten. H v. 16 lautet ובפקדו וכרגשו; das ist: „und wenn er sie besucht und wenn er sich heftig bewegt", was nach v. $16^{c}$,wenn er auf sie herabsteigt, zittern sie", nicht pabt. SM ändert darum den Text und

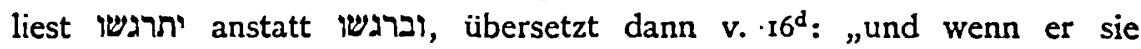
ובפקדו וכרנשו mustert, wanken sie (die Berge)“. Wahrscheinlich aber sind Glossen zu ברדתו.

I $83^{2}$ SM: "Vergnüge dich nicht bis zu ausgelassener Schwelgerei“" MD: "Habe keiné Freude an ausgelassener Lust". $H$ hat שמץ תענוג steht hier, wie häufig, fur על und gehört zu שמח, als לy des Gegenstandes, vgl. Jes 916392 Jon 46. So auch mit Recht R. Wie aber $S_{M}$ שמע auffabt, ist nicht klar. MD ändern das Wort in שמע, los. lassen. Das Loslassen der Lust ist ausgelassene Lust.

$207^{\mathrm{b}}$ MD: „doch der Tor achtet nicht auf die Zeit", nach H וכסיל לא ישמר עת. SM: ,aber der Übermütige und der Spötter achtet nicht auf die Zeit". Er will nl. anstatt וכסיל mit Gr ול ולץ lesen, wodurch der Spruch seine kernhafte Kürze verliert.

$2520^{\circ}$ SM: „eine keifende Frau"; doch das ist keine gute Über- 


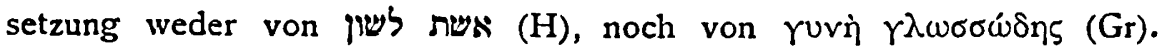
MD: ,eine geschwätzige Frau".

$252^{\text {d }}$ SM: „ein. Weib, das seinem Mann nicht beisteht". Er nimmt אשר Piel im Sinne von stärken, führen, was h. 1. jedoch nicht paßt, da Sirach nicht will, daß die Frau so viel Macht übt, vgl. 25 22. Man denke also besser an das andere mit MD: „eine Frau, die ihren Mann nicht beglückt".

$3025^{\mathrm{b}}=\operatorname{SM} 33^{13^{\mathrm{b}}}$ (S. 52): „Fur den Frohlichen ist der Schlaf wie Leckerbissen, und alles, was er i 1 t, kommt auf ihn". MD: „Der Schlaf eines guten Herzens ist statt (d. h. wie) Leckerbissen, und seine Speise bekommt ihm". H hat: שנות לב טוב תחת מטעמים ומאכלו "עלה עליו. SM's ,kommt auf ihn" ist unverständlich; im Glossar erklärt aber SM gut: „schlägt bei ihm an“.

31 $6=\mathrm{S}_{\mathrm{M}}$ 346. MD: „Viele sind verderbt durch das Gold (buchstablich: Verderbte des Goldes), und wehe dem, der aut Perlen sein Vertrauen setzt“. SM: „Viele haben sich am Golde gefangen רבים היו חבולי זהב והבוטח חבולי .על פנינים

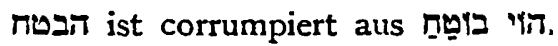

$311^{\mathrm{b}} \mathrm{MD}\left(=\mathrm{SM} 34^{19^{b}}\right)$ : "und auf seinem Bette bricht er nicht". In 34 19: , השיק שוץ bedeutet überlaufen, überströmen Joel 2244 13 Ps 65 ro d. h. „brechen", sich übergeben. Sir. nimmt Rücksicht auf diejenigen, die zuviel essen und trinken, im Gegensatz zum verständigen Menschen, dem weniges genügt v. $19^{2}$. SM denkt an שנק, LEVI alles unnötig, weil der Text von $\mathrm{H}$ einfach und gut ist.

$322^{\mathrm{c}}$ (SM $352_{\mathrm{g}}^{\mathrm{c}}$ ). MD: ,und (damit) du der Führung wegen Ehre geniebest"; SM:•, und (damit) du um deines Anstandes willen Ehre

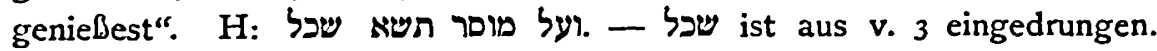

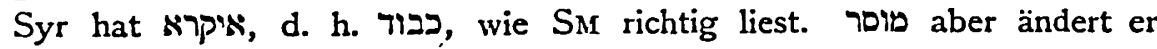
ohne Grund in מוספו, Zucht, bedeutet hier die Leitung oder Fuhrung des Tisches durch den Zechmeister, vgl. v. 1.

329 ( $\mathrm{S} M 35$ 9). MD: „Erhebe dich nicht unter Greisen und behellige Fürsten (Vornehme) nicht". SM: „Inmitten von Fursten nimm dir nichts heraus, und Greise behellige nicht mit vielen Fragen". $-\mathrm{H}$ liest in v. $9^{\mathrm{a}}$

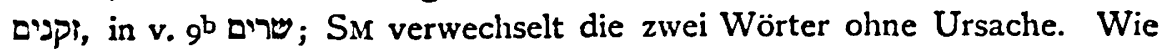
$\mathrm{H}$ es hat, ist es natürlich und gut. - Mit vielen Fragen (SM) steht

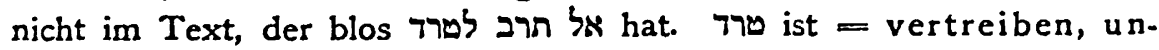
ruhig machen. Also: mache die Leute nicht unruhig, behellige sie nicht. 
32 12a (SM 35 12) MD: „Während der Mahlzeit sprich nicht viel“ fehlt bei SM ohne Ursache, da H lautet: בעת שלחן אל תרבה דברים. Dagegen ist v. $12^{a} \mathrm{SM}$, d. h. v. $12^{b}$ in $\mathrm{H}$ zu streichen, da es Glosse ist

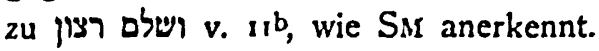

32 13a MD: und für alles danke; $\operatorname{SM} 35$ s3: und zu dem allen preise.

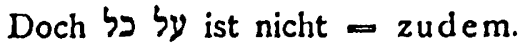

$3520 \mathrm{MD}$ : "Bitterkeit bringt Gnade, das Wehgeschrei eilt zu den Wolken"; SM 32 20: „Die Klage des Gequälten ist ein wohlgefalliges Opfer und der Hulferuf erreicht die Wolken". Vgl. Ss's Kommentar S. 315. Der Text ist fast unverständlich. H lautet: תמרורי רצון הנחה וצעקה ענן חשתה. Ich schlage vor תמרורים רצון הנחו וצעקה ענן חשה. Nach שוש, = eilen, der Akkusativ der Bewegung. Sinn: Diejenigen, die von Menschen Bitterkeit erfahren, finden Gnade, Wohlgefallen bei Gott; die Klage eilt zu den Wolken und erreicht sie (d. h. den Himmel). - Alles sehr unsicher.

$35^{22^{b}}$ (SM $3222^{b}$ ). SM: „Auch der Herr wird nicht zögern"; MD: "auch wird der Herr nicht zögern", $H$ גם אדון לא יתמהמה.- Häufig bezieht גich, obwohl vorn stehend, auf ein spateres Wort, vgl. Gen 3221 Hos 6 il usw. GES.-BUHL Wb. s. v.

37 Ir² SM: „mit dem Weibe wegen einer Doppelehe“; MD: „(Berate dich nicht) mit einem Weibe uber seine Feindin". - Obgleich es moglich ist, daß bei צר an die zweite Frau in der Doppelehe gedacht ist (vgl. I Sam I 6), ist es nicht sicher, und also die buchstäbliche Übersetzung der freieren vorzuziehen.

38 16b SM: „und entziehe dich nicht bei seinem Abscheiden“; MD: "und entziehe dich nicht der Sorge für seinen Leichnam". - H ו ו תתות , buchstablich: „und verbirg dich nicht bei seinem Leichnam d. h. wenn er ein Leichnam geworden ist". Dabei ist. גול nicht mit Gr, Syr, $\dot{S}_{M}$ als Begräbnis aufzufassen; denn das Wort bedeutet immer Leichnam.

39 17 SM: „Durch sein Wort stellt er die Leuchte an die Himmelshöhe und durch den Spruch seines Mundes in seine Kammer". Dieses in seine Kammer ist Übersetzung von หรุ, aber sie gibt keinen Sinn בדברו יערוך נר במרום ובמוצה פיו : אוצרו selbst èbensowenig. H lautet

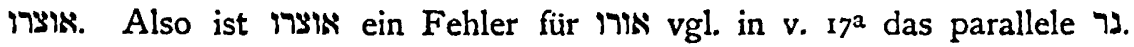
So lesen MD und übersetzen demzufolge den ganzen Text: „Durch sein Wort stellt er die Lampe an die Himmelshöhe und durch den Spruch seines Mundes seine Leuchte".

409 SM: „Pest und Blutvergießen, Kornbrand und Dürre, Zerstörung 
und Verwustung, Hungersnot und Plage“. MD: „Pest und Mord, Fieber und Schwert, Zerstörung und Verwustung, Hungersnot und Tod". תרזרר bedeutet nie Kornbrand, sondern immer und überall Fieber, vgl. Dtn 2822 Spr 2621. מקרב und תein.

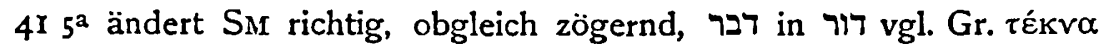
גנכמ אוי להם גורי רשע und übersetzt: „und ein verfluchter Sproß sind die Welpen des Gott-

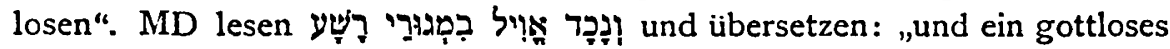
במגור Geschlecht weilt in den Wohnungen des Bösen". Auch P liest

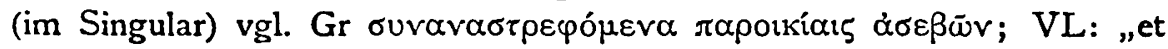
qui conversantur secus domos impiorum".

4I 19a SM: „(Schäme dich) vor dem Orte, wo du Schutzbürger bist, des Hochmuts"; MD: „,vor dem Orte, wo du wohnst, des Betrugs". H ist ebenso unsicher als 7 , das $\mathrm{S}_{\mathrm{i}}$ is lesen will. Symm. hat $\pi \lambda$ okñ (Betrug). Es könnte sein, daß 7 ein feindliches Verhalten bedeutet. - Alles unsicher.

41 20b Sm: „eine Hure zu betrachten“, MD: „die Frau des Nàchsten anzusehen". מהביט אל אשה זרה Richtig Frankenberg ZAW XV, 120:, זעשה זרה, vor deren Umgang der Verfasser warnt, ist offenbar eine verheiratete Frau, eine Yuvì ü $\alpha$ avopos, Prov 216 f., 6 24, $29 \mathrm{ff}$., die den Fremden bei sich einläbt". Also nicht eine Hure.

$427^{\mathrm{a}}$ SM: „Für das Hinterlegte gehört sich Zahl und Gewicht"; MD: „über den Ort eines Depositums geschehe eigenhändige Unterschrift", buchstäblich: „schreibe die Hand“. H hat: על מקום מפקד יד תספור. מפקד steht in margine, in textu תפקד, was auch SM mit Recht verwirft. Doch mit Unrecht streicht er מקום, das den Ort des Depositums (מפקד)

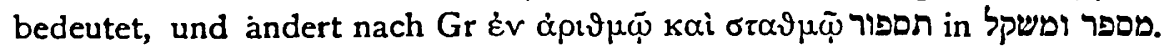
$429^{a}$ SM: „Eine Tochter ist für den Vater ein Schatz, der ihm Unruhe macht"; R: „eine Tochter ist für ihren Vater ein Schatz, der ihn wach hält". Sie lesen שקד (mit Gr àypurvía); MD lesen mit H שקר, ebenso P: „filia patris thesaurus fraudis 'est“. Auch der Talmud (Sanh. 100) hat שקר gelesen, das er mit wiedergibt. Darum MD: „Eine Tochter ist für ihren Vater ein betrügerischer Schatz"; d. h. ein Schatz, auf den er kein Vertrauen setzen kann.

$437^{\mathrm{b}}$ SM: ,von der lieblichen Leuchte, die zuletzt sich verfinstert"; MD: „die liebliche Leuchte, die bei ihrem Kreislauf (Umlauf) sich verfinstert". Denn תקופה ist Kreislauf, Umlauf (cf. Ps 197 I Sam I 20 usw.), nicht zuletzt. Der Sinn ist, dab allmählich das Licht beim Umlauf abnimmt. 


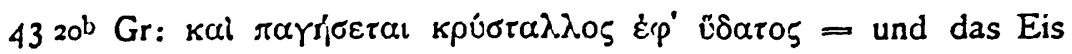
wird dick auf dem Wasser. H: וברבְכָה

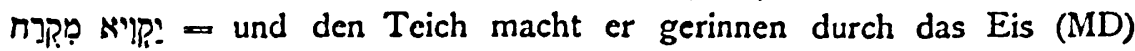
oder vor Kälte; SM: und wie mit einer Kruste macht er den Teich gerinnen. R: "und durch sein eisiges Wesen lält er Eis gefrieren".

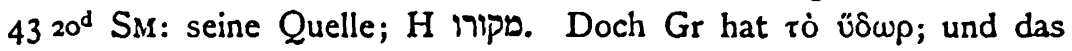
Suffix ist schwer verständlich. MD: „die Quelle“ Vulg. lacum, הִ̣̂.

$4326 \mathrm{H}$ רצוצו רונצ lies.

$433^{\mathrm{b}}$ Sir: „.. . von diesen Werken“; MD: „.. . von seinen Werken". H ממעשין

$44^{162}$ Über Henoch handelt wiederum 4914 , was BICKELL veranla@t, hier den Vers zu streichen; doch er darf h. 1. nicht fehlen; eher ist die zweite Erwähnung 49 I4 uberflüssig. Indes wird auch Davids, Hizkias und Josias 494 zum zweiten Male gedacht. - Der Text lautet in

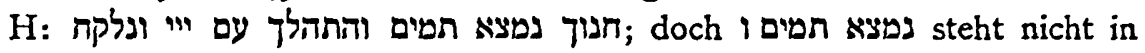
Gr und ist gewiß aus v. 17 entnommen. SM streicht auch nלsi, das Gr hat, und das auch schwerlich fehlen kann, weil die Himmelfahrt Henochs das v. 16 $^{\mathrm{b}}$ beabsichtigte Wunder und Zeichen seiner auferordentlichen Gottesfurcht für alle Geschlechter war.

44 17b SM: „zur Zeit der Vertilgung wurde er ein Nachwuchs“; MD: „zur Zeit der Vertilgung wurde er ein Stammvater". R: „wurde er ein Fortpflanzer". $\mathrm{H}$ hat $\rceil$ ךלת, d. h. einer, der neue Sprossen

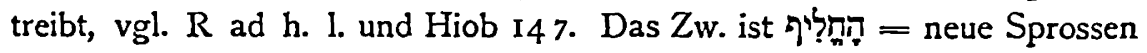
treiben.

$4417^{\mathrm{d}}$ SM: „Durch seinen (Noahs) Bund blieb aus die Flut"; MD: „des Bundes wegen mit ihm hörte die Flut auf". Ebenso V und P Man könnte gegen „blieb aus" einwenden, daß die Flut gekommen war; aber-SM meint: „sie kehrte nicht wieder"s. Doch, wie er selbst zugibt, spricht Gen 8 Iff. für die andere Auffassung von 3 ח

44 21 $\mathrm{b}$ SM: „daß mit seinen Nachkommen sich segnen sollten die Heiden“; MD mit V und P: „daß er (Gott) durch seinen Samen Völker

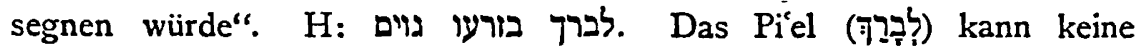
reflexive Bedeutung haben; zudem ist „der Wechsel des Subjekts im Folgenden dabei unbequem" (SM).

$442^{c}$ SM: „Der Bund aller Vorfahren wurde gelegt“; MD: „Den Bund mit jedem Ahn schenkte er ihm", d. h. sagte er ihm zu, vgl. Gen . 263 24. H: ברית כל ראשון נתנו. SM will das Suffix in נתנו nicht dativisch nehmen, doch ist die Richtigkeit dieser Auffassung aus vielen Bibelstellen nachgewiesen von KöNIG Syntax (1897) S. 8 j 
(Plur. pf. Nif.) als Prädikat zu ברית כל רöglich sei, wird von SM wohl behauptet, doch nicht bewiesen.

$4423^{\text {b }}$ SM: , und er bevorzugte ihn im Segen“; MD: „und er erkannte ihn als Erstgeborenen", buchst. in der Erstgeburt, oder im Erstgeburtsrechte. $\mathrm{H}$ ist zweifelhaft. Der Text lautet ויכוננהו בברכה; am

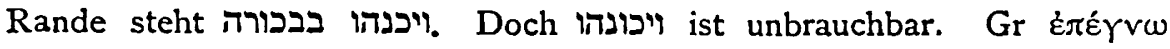

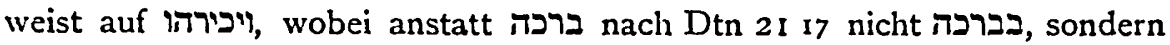
bloß הכיר . Baßtedeutet auch nicht bevorzugen, sondern erkennen, anerkennen.

$452^{2}$ SM: „Er gab ihm den Ehrennamen eines Gottes“; MD: „Er stellte ihn hin als einen Gott". P unsicher; nur אלהים ist lesbar. SM suppliert mit Recht ויכנהו, übersetzt aber ויכבדהו. Vor liest er ein 2; das muß jedoch ein $\supset$ gewesen sein, denn "Sirach hat Ex 4 I6 7 I im Sinn" (SM)."

$45^{6 a}$ SM: „Und er erhohte ihn gleich einem Heiligen“; MD: „und er erhöhte einen Heiligen ihm (Mose) ähnlich". H nach SM וירם כמוהו קדוש; also ist קדוש, Objekt von das ohne Suffix steht. Doch die Wort-

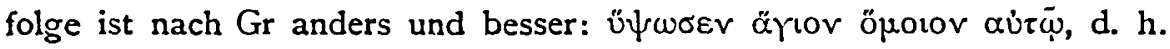
וירם קדוש כמהו

$454^{c}$ SM: „er machte ihn stark durch seine Ehre“; MD: „er machte ihn dienen in seiner Pracht". H hat: וישרתה בכבודו, was SM ändert in ו'יאשרהו. Dies wäre jedoch: und er pries ihn, oder und er machte

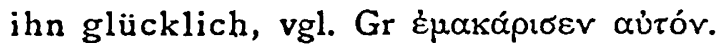

במלאים 45 I1 vgl. Ex 257359 .

$45 \mathrm{I3}^{\mathrm{c}}$ SM: „Einem einzigen seiner Söhne wurde das gestattet", nl. die hohepriesterlichen Kleider zu tragen. MD: „bloß seinen Söhnen hat er sie anvertraut". H nach $S_{M}$ : האטמן בדר לבניו כוה. Dies ubersetzt er nicht richtig; denn בדד ist nicht = ein einziger; auch steht ל לנרון ל vor, nicht vor בדז, angenommen daß dies einen einzigen bedeuten könnte. Also ist hier die Rede von den Söhnen Aarons, wie auch $\mathrm{P}$ liest und übersetzt; nur hat er לו ולבנים. Die Schwierigkeit lag für SM natürlich darin, $\mathrm{da} b$ nach dem Hexateuch nur einer der'Söhne, Eleazar, den Ornat getragen hat. Im Texte liegt jedoch nicht, daß die andern ihn auch trugen, sondern die Bewahrung des Ornats ihnen und den folgenden Aaroniden, d. h. der Familie Aaron, anvertraut worden ist. - Vom Tragen des Ornats war bis v. $13^{b}$ die Rede, wo gesagt wird, dab nie ein 7 ihn tragen soll. Mit diesem Ausdruck ist kein "Unheiliger", (SM) sondern ein „Fremder" d. h. von anderem Stamme und Geschlechte, ein "Unberufener", gemeint.

2 SM denkt offenbar mit Recht an כִנְָ Jes $445^{\circ} \cdot$-[K. M.] 


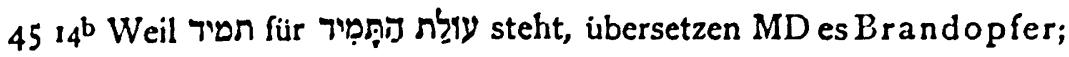
$S_{M}$ ständiges.

$45^{2}$ b SM: „Und er bestimmte die Auslese ihm zum Anteil"; MD: "Und die Schaubrote sollten sein Anteil sein". So auch P und R. Von לחס פנים steht in der Hds. von $H$ leider nur das letzte $\square$, dann folgt חלקו. Aus dem $\square$ geht jedoch deutlich hervor, daß ויכון ראשית, wie SM liest, nicht in $\mathrm{H}$ stand. Aber Syr hat hier d. h. „und die Brotreihe", wonach NÖLDEKE ( $P^{2}$ S. 245) לחם מערכת, P2 besser des $ם$ wegen לחם

$4525^{\circ}$ SM: „das Erbe eines Mannes vor dem Angesicht seiner Herrlichkeit". So auch $\mathrm{P}^{2}$ : „Hereditas viri coram gloria eius". Diese Übersetzung befolgt H im Ms.: נחלת הש לפני כבודו. Aber der Sinn befriedigt

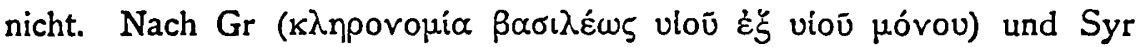
(das Erbe der Könige erbte er allein) liest Pr richtig נחלת מלך לבנו לבדו לברו lasen. Darum MD: „es war das Erbe eines Königs für seinen Sohn allein.“

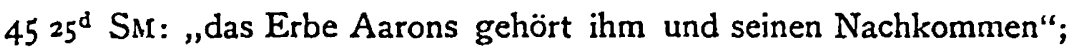
MD: „das Erbe Aarons war für alle seine Nachkommen“. $R$ wie SM; $P$ wie MD. $H$ hat ebenso ונחלת ההרון לכל-זרעו. R verwirft die LA wegen

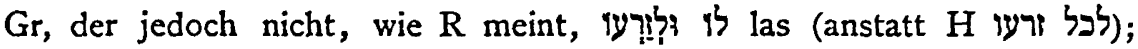

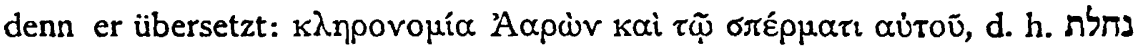
אהרון ולכל-זרעו, was keinen Sinn gibt. SM verwirft die LA H's, weil לכל זרעו, bedeuten würde, daß jeder Nachkomme des Pinehas Hoherpriester werden konne“. Doch erstens ist h. 1 . die Rede von dem Erbe des Pinehas, d. i. von den Einkünften; und außerdem hat, was SM nicht will, daß Sirach es behaupte, dieser eben gesagt v. $24^{\text {cd }}$ : „daß ihm (Pinehas) und seinen Nachkommen das Hohepriestertum gehören sollte in Ewigkeit".

$46{ }_{4} \mathrm{SM}_{M}$ und MD: „durch ihn"; $\mathrm{SM}_{M}$ gibt in $\mathrm{H}$ בידי, was Druckfehler ist statt בידו. P: ,in manu eius (stetit sol)", nicht richtig.

$4613^{c}$ SM: „der Verlobte des Herrn im Prophetenamt"; MD: „der Geweihte des Herrn durch das Prophetenamt:“. H נזיר " Den Verlobten bedeutet 1 ile. Falsch R: „der Naziräer Jahwes".

$4613^{\mathrm{d}}$ SM: "Samuel, der als Richter und Priester waltete"; MD: "Samuel der Richter, der auch als Priester diente“. H שמואל שופט ומכהן.

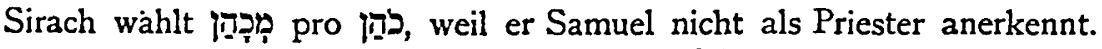
. $476^{\circ} \mathrm{Sm}$ :" "Als er die Krone aufsetzte, führte er Krieg“; MD: „Wenn er die Krone aufsetzte, führte er Krieg", nach der Vorstellung, daß der Krieg fuhrende König die Krone trug, vgl. II Sam I 10. 
47 7 bM: „Und er machte zu Schanden die feindlichen Philister"; MD: „und er erschlug die feindlichen Philister“. H ויתן בפלשתים ערים, was $R$ ubersetzt: ,und er legte unter den Philistern Festungen an"; $\mathrm{P}^{2}$ „et fecit in Philistum oppida". Doch besser ist, mit Gr (úrevavrious) das dritte Wort צים zu lesen - $-\checkmark$ und $y$ werden häufig verwechselt,

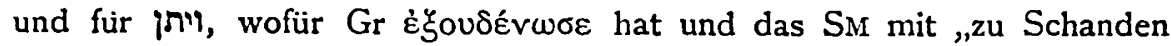

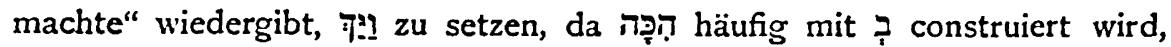
vgl. z. B. II Sam 23 ro, wahrend הכניע, demütigen, zu Schande machen bloß mit dem Akkusativ konstruiert wird.

$478^{\mathrm{d}}$ ist der Text so verderbt und unsicher, daß die Übersetzungen

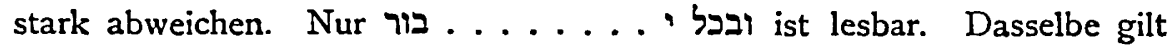
von $\mathrm{H} 47$ roa und rob.

47 15 SM: „Die Erde uberdecktest du mit deiner Seele und fabtest in dich Lehrrede [wie das Meer]". MD: „Die Erde überdecktest du mit deiner Vernunft und nahmst Kenntnis in dich auf wie das Meer". Aus dem Inhalte von a folgt, daß auch in b die Weisheit (Salomo's) behandelt sein muß. H hat in a ארץ כסית בנפשר, in b ותקלט במרום שירה. Von P wird תקלט gelesen und der ganze v. b wiedergegeben: et fecisti de coelo cantica laudis, während $V$ (besser mit Rücksicht auf ubersetzt: „und in der Himmelshòne sammeltest du Lieder". $-\mathrm{H}$ ist offenbar verderbt, weil in jeder Hinsicht unpassend; תקלט ist ursprunglich

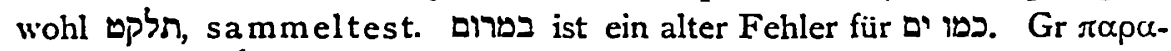

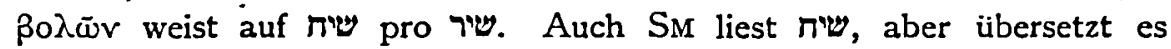
mit Lehrrede, das im Kontext nicht pallt. Wohl ist es 324 Rede, aber im Sinn von Geist; eigentlich ist es v. $15^{a}$ synonym mit נפש vgl. I Sam I 15 Ps 42, 5 und mit ח3מה 324. Vielleicht wäre auch dort besser Geist, Vernunft übersetzt worden.

$4723^{a}$ SM: „Und Salomo entschlief in Verzweiflung“; MD: „und Salomo legte sich zu seinen Vätern". SM gibt $\mathrm{H}$ folgendermaßen wieder: וישכב שלמה טיואש Nun ist jedoch nach $P^{x}$. vom Faksimile eigentlich nur $\forall$, der letzte Buchstabe, ganz sicher; nach $S_{M}$ aber ist dieser so wenig sicher, dab selbst der Raum für $\boldsymbol{E}$ 'nicht hinreicht. Nach ihm ,scheint auf der Photogr. ein $y$ zu stehen, aber das war dann aus $\kappa$, das auf den Faks. deutlich erscheint, korrigiert". Dies ist unverständlich; ich schließe jedoch daraus, da $\$$ beide, $y$ und $\kappa$, im Ms. noch wiederzufinden sind. Da nun beide Buchstaben auch vorkommen in עם אבתיו, so halte ich dafür, dab die zwei genannten Buchstaben Reste dieses Ausdruckes sind,

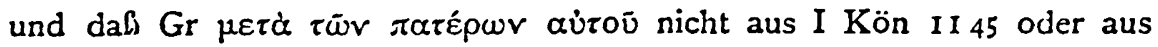
der Willkür des Übersetzers (SM), sondern.aus $H$ stammt. 


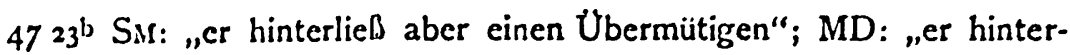
ließ cinen Soln aus seinem Geschlecht". Nach S.M hat H: ויעוב אתריו טגון, doch fugt SM in der Note hinzu: ,von מנו nur die unteren Ränder",

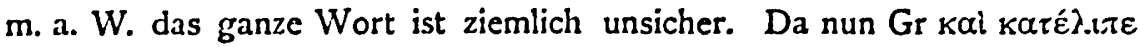

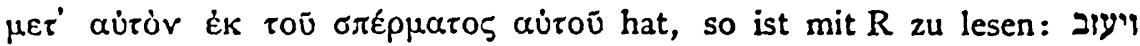
אחריו מִּרְעו מורעו ist soviel als $ן$ und genügt vollständig.

$4812^{a}$ SM: „Als Elia in der himmlischen Kammer verschwand"; MD: „Als Elia durch das Gewitter verhullt ward". Nach SM hat $H$ אליהו שבאוצר נסתר. Wäre dem so, so wäre dennoch die Übersetzung von אוצר durch himmlische Kammer nicht ricbtig; ' $k$ kann Schatzhaus, Schatzkammer, aber nicht himmlische Kammer bedeuten. Und wie sonderbar ist die Vorstellung: Elia in der himmlischen Kammer verschwunden! Doch das zweite Wort in $\mathrm{H}$ ist nicht ganz lesbar, bloß

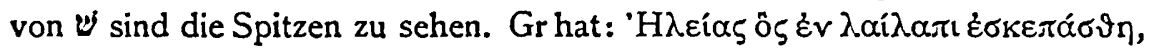
was Übersetzung ist von אליהו שבסערה נסתר, wie P richtig liest und II Kön 2 II bestatigt. So muß $\mathrm{H}$ gelautet haben und wieder gelesen -werden.

48 1 $3^{\mathrm{b}}$ SM: ,von seinem Orte aus wirkte Prophetenwunder sein Fleisch“. MD: „und von seinem Grabe aus wirkte sein Fleisch prophetisch". SM sagt jedoch auch im Kommentar, dab מתחתיו = aus seinem Grabe bedeutet, vgl. 49 rob.

$4822^{a}$ SM: „Denn Ezechia tat was dem Herrn gefiel“; MD: „denn Ezechia tat das Gute". Sie folgen mit P und R dem Text in $\mathrm{H}$ : כי עשה יחוקיה את־הטוב (obgleich nicht der ganze Stichos deutlich lesbar ist).

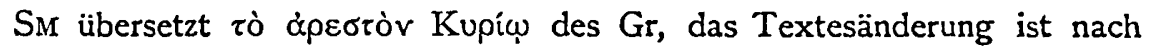
II Kön I8 3 und II Chron 292 : עשה הישר בעיני יהוה (P).

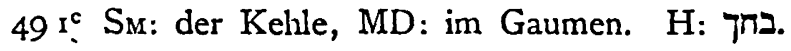

$492^{2}$ SM: „Denn er grämte sich uber unsere Abtrünnigkeit"; MD = SM. H: ני נחל על משובתינו. Dist נחל מחלה ist entweder verkürzt aus נחלה, Nif. v. חלה, cf. Am 66; oder נחלה מלה של zu lesen. P: ,et tulit abominationes impietatis" ist unverständlich und unbegründet.

49 6b SM: „und es verödeten die Straßen nach ihr"; MD: „und verwüstet lagen ihre Straßen“. $P$ und $R$ fassen וישמו transitiv auf als Piel, doch sאו ארחתיו Dehlt vor. Diese sind nach $S_{M}$ und $R$ die Straßen, oder Wege, die nach Jerusalem hinfuhrten. Das könnte doch nicht wohl durch das Suffix ausgedrückt werden.

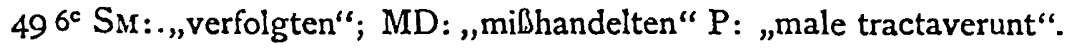
H: ענודו.

$497^{a}$ SM: „Und auch Hiob [nenne ich als Propheten]“; MD: „Und 
auch Hiob will ich erwàhnen". H: וגם הזכיר את איוב. SM, R, MD ändern הזכיר, diest man mit $\mathrm{H}$, so sagt Sirach: „er, Hesekiel, hat Hiob erwähnt", was sich dann beziehen würde auf Hes 14 14. Doch dann müssen v. 1o "die zwölf Propheten" auch Objekt von sein, weil kein neues Zeitwort folgt. Da jedoch die zwölf Propheten nicht von Hesekiel erwähnt werden, ist der Sinn, daß Sirach selbst sie nennt, und mit Rücksicht darauf ist אוכיר zu lesen, was dann auch für die Erwähnung Hiobs gilt. - Mit Unrecht aber liest SMr, und ebenso R, nach Hiob נביא, das in Syr fehlt. Von diesem Worte ist fast nichts lesbar: ,von $\mathrm{J}$ der Fuß, $\boldsymbol{N}$ schattenhaft, an der Stelle von ב Spuren von "', woraus ich folgere, daß eher oder wenigstens ein Wort mit $ש$. Da dies aber sehr unsicher ist, scheint es besser, das Wort unubersetzt zu lassen.

$5029^{\circ}$ SM: „denn die Furcht des Herrn ist ihr Wesen". MD: „denn die Furcht des Herrn ist das Leben“. H: כי יראת "י תי" SM ändert חיים, d. h. ,,das Wesen des in diesem Buch Enthaltenen“. Doch I. ist חקוcht $=$ Wesen; 2. ist das Suff. Plur. unverständlich und jedenfalls nicht auf den Inhalt des Sirachbuches zu beziehen. חיים scheint ihm (SM) zu allgemein, doch warum? Prv I 427 I 23 lehren fast dasselbe: dab Gottesfurcht eine Lebensquelle ist oder zum Leben fuhrt. Doch meint SM weiter, der Spruch „,befriedige deshalb nicht, weil so die Gottesfurcht ohne weiteres an die Stelle der Weisheit träte“. Sirach sagt es jedoch sehr deutlich v. 28: wer über seine Worte nachsinnt, wird weise; wer nach den Vorschriften der Weisheit tut, erwirbt sich die Gottesfurcht, welche das wahre Leben gibt und ist. $\mathrm{Er}$ identifiziert also die Weisheit und die Gottesfurcht nicht, sondern unterscheidet sie, ohne sie zu scheiden.

5 I $17^{b}$ (Waw). SM: „Und ich gebe Bekenntnis dem, der mich anstachelte" MD: „und demjenigen, der mich lehrte, gab ich Lob“. H ולמלמדי אתן הודאה. SM vergleicht Hos 10 II Jer 31 18; aber an diesen Stellen, wo das Pu'al vorkommt, ist von Tieren die Rede. Doch überall sonst, wo למד in Piel gebraucht-wird mit Bezug auf Menschen, bedeutet es lehren. So auch hier. Richtig ist bei SM: „gemeint ist aber Gott".

5 I $19^{e}$ (Cheth): SM: „Meine Hand öffnete ihre Pforte“; MD: „M. H. offnete ihre Pforten's. H שעריה. So auch P: portas eius.

$5120^{\circ}$ (Lamed) SM: „Verstand gewann ich mir durch ihre Lenkung“; MD: „Einsicht erwarb ich mir von Anfang an". So auch $R$, der aber "durch sie" nach „erwarb" zufügt. Das steht jedoch nicht in $H$, der 
lautet ל2. Die Änderung von לב קנית לה מתחה in ist nicht schlecht, weil sie Sinn gibt; mehr aber leuchtet die von in in ein, besonders weil auch Syr so liest. - Gegen מתחלתה wendet SM ein, dal das Suffix hier nicht bedeuten kann: "von dem Augenblick an, als ich zuerst bei ihr weilte". Darin hat er recht; und auch "vom Beginne der Existenz der Weisheit an" kann Sir. nicht haben sagen wollen. "Das Suffix zu streichen hat man kein Recht", sagt er weiter. Indes

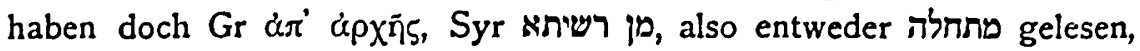
oder מתחלתה als Aram. determinatus (eig. מתחלתא) aufgefabt, was es auch sein kann. Jedenfalls gibt, trotz $S M$, ,von Anfang an“ den besten Sinn, vgl. v. 13 und 14: ,in meiner Jugend". Was SM anstatt מתחלתה vorschlägt, empfiehlt sich nicht, weil „durch ihre Lenkung“ nur מתחלתו sein könnte.

5I $20^{\text {d }}$ (Lamed) SM: „darum werde ich nie von ihr lassen“; MD: „darum habe ich sie nie verlassen". $H$ ist für die Hälfte unlesbar; nur

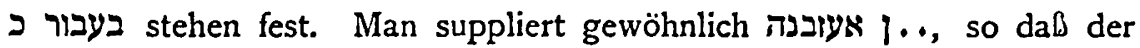
ganze Halbvers lautet בעבור כן לא אעובנה. Doch ist es wahrscheinlicher, daß Sirach als letztes Wort der Zeile עובתיה schrieb, weil auch v. 2rb, nachdem in a gesagt war: „mein Inneres war unruhig, sie zu suchen", das Perfectum folgt: „darum gewann ich sie zu gutem Besitz“. 